\title{
Communication in a globalized multicultural society: ethnic mentality aspect
}

\author{
Liubov Drotianko ${ }^{1, *}$ and Maria Abysova ${ }^{1}$ \\ ${ }^{1}$ National Aviation University, Kosmonavta Komarova ave. 1, Kyiv, Ukraine
}

\begin{abstract}
The purpose of the article is to set out the peculiarities of the forms of communication in a multicultural society in the context of globalization through the lenses of ethnic mentality component of intercultural interaction. The problem of intercultural interaction, mutual understanding and consent in the communication of different peoples living together in a single society, is under review by the world and domestic scientific and philosophical public. The article argues that in ontological terms, interethnic communication is a complex multidimensional sociocultural phenomenon, which is studied within interdisciplinary approach by philosophy, political science, sociology, psychology, communication theory and other socio-humanitarian sciences. In the era of globalization, integration processes are intensifying. As a result, there are new political, economic, social and cultural conditions for the coexistence of different ethnic groups in a multicultural society. Since ethnic mentality characteristics have a significant impact on the communication processes, one can not underestimate their place and role in the intercultural communication of people. This factor contributes into new communicative forms of representatives of various ethnic groups, which shape the multicultural space of social being in the conditions of globalization.
\end{abstract}

\section{Introduction}

Globalization processes that have embraced all spheres of world society being, give rise to mostly new phenomena of civilization development. Among them there is the phenomenon of multiculturalism, which arose at the intersection of economic, sociopolitical, religious and other relations of countries, peoples, ethnic groups within one society. The essence of this socio-cultural phenomenon is studied and ambiguously evaluated in various fields of social and human sciences, which reveal both its positive trends and hidden threats. In particular, F. Fukuyama raises the question of survival of universalist forms of cultural identity under the attacks of the fundamental faith in multiculturalism, which goes beyond the boundaries of cultural diversity and requires the promotion of cultural differences [5, p. 382-383]. The main threat is based on moral relativism, which does not promote dominance of any particular set of values in the society.

\footnotetext{
* Corresponding author: drotlg@nau.edu.ua
} 
The dangers implied in the multiculturalism for a nation state are being studied by a Russian scientist N. Polyakova. In particular, she points out to two of them. Relying on human rights, primarily on the right to travel, different ethnic groups require transparent borders and the right to be present and to live within any national-state formations. In addition, multiculturalism both as a principle and a practice may have a negative impact on the socio-cultural space of the national state. Immigrant ethnic and religious minorities protect their culture and identity, which prevent and sometimes encourage them for an active protest against assimilation. Predictably, this state of affairs result in artificial gaps and disruptions of the homogeneous cultural and normative space of the national-state [6, p. 369], and ultimately - to political conflicts on the ethnic-cultural and religious grounds.

A multicultural society, therefore, is not a simple coexistence of individuals with different ethnic origins, but a social system within which ethnic social structures are viewed as a part of the social structures of a society. A multicultural society is not harmonious by definition. It quickly becomes controversial if it encounters different cultural groups, whose position is aggravated by social inequality. In this regard, the problem of the balance between class, ethnic, national and state interests, taking into account the factor of ethnic mentality is debatable.

\section{Materials and methods}

The multidimensionality of the ethnic mentality revealed in the process of communication requires a wide set of methodological settings and principles of the analysis of sociocultural phenomena: - the principle of ideological and theoretical continuity, which allows exploring the the socio-genesis of ethnic groups and nations and the communicative forms of their interactions that are correlated with it; - the principle of concreteness, orienting towards the identification of the ontological foundations of the forms of communications among ethnic groups and nations; - the principle of historicism, aimed at the analysis of communicative phenomena in the context of their ethnic mental changes.

A variety of methods used in this socio-philosophical study include: - the method of comparative philosophical analysis, regarding the correlation of the results of genesis of ethnic groups and nations and communicative forms appropriate to it; - the method of synthesis, which allows to generalize the material obtained in the study with the factors of communication caused by globalization;- the method of historical and philosophical reconstruction, within which scientific scientific concepts of the results of the genesis of mentality of ethnic groups and nations, change the very nature of communication among them.

The theoretical and methodological bases are works written by M. Nussbaum, S. Benhabib, N. Bissoondath, C. Castles, J. Ceaser, I. Clark, J. Clifford, R. Cox, N. Glazer, D. Hollinger, W. Kymlicka, D. McGhee, C. McKenzie, J. Levy, L. Lippmann, C. Troy, C. Trotman, R. Robertson., J. Zubrzycki, M. Wieviorka and others that reveal the conceptual foundations of globalization and multiculturalism, the phenomenon of glocalisation and the theory of regionalism; trends in the development of transnational cultural space (F. Kessidi, A. Panarin, A. Utkin, M. Epshteyn, V. Der Zee, M. Miville, J. A. Banks); the concept of the Information society, according to which acceleration and globalization of communication processes take place at the new stage of society's development (D. Bell, M. Castells, A. Toffler, F. Webster, M. Poster).

Since ethnic culture is inseparable from its language, the methodology of philological and semiotic analysis has been required (M. Bakhtin, A. Wierzbicka, Yu. Lotman, R. Bart, G. Hofstede). 


\section{Results}

A long-standing debate of the concepts of "ethnic group" and "nation", features and the mechanism of their formation reveals the exceptional complexity of these phenomena. The main and, to a certain extent, polar views on this problem are the following ones: the nation as a co-citizenship (political, territorial or civilian) and the nation as a form of ethnic existence (ethnonation). The supporters of the former model - constructivists (E. Gellner, B. Anderson) - believe that the nation is a community of people, united not so much by the past (the origin and language of community), but by the future - a project of its own existence and the will to its implementation. In this sense, a nation is always a process, not a result of it. The joint plan for the future contributes into the consolidation of people of different origins, races, denominations, alleviates the original ethno-cultural differences, moulds the relative homogeneity of the language. That is, the constructivist model deals with a nation as a result of the implementation of a certain national project developed by a small group of intellectuals. Initially, supporters of this concept state, the idea of the nation arises as a reflection of the needs and conditions of the time. At the same time, the ethnic identity of the population is just a starting point, the foundation and it does not guarantee or determines the emergence of a nation on its basis. If the ethnos is a predominantly culturalspiritual formation, the nation is a political one. The main components of the nation are the historical territory, the political and legal equality of members, the common civil culture and ideology. The transformation of an ethnic group into a nation requires focused efforts. Ethnicity is considered as a concomitant cultural phenomenon that is arranged by the nation's dominant group or set of groups. Subordination of ethnic civilians has been reflected in a number of Western European languages, in which the word "nationality" is derived from the term "nation" referring citizenship (for example, in French - nationalite").

In the "ethnic" or primordialist conception (C. Geertz, A. Smith, Yu. Bromley, L. Gumilyov), the ethnic factor plays the formative role for the nation. A nation is viewed as a community of people, united primarily by their common origin, culture and the mother tongue. Thus, the primary basis of the nation is the ethnos at that stage of sociocivilizational maturity, when it acts as a self-sufficient socio-cultural system and manifests the aspiration for political self-determination. Everything that remains beyond the borders of the nation in the process of its forming turns to be perceived as alien and potentially hostile. The nation withdraws into itself, its own national interests. The ideology of nationbuilding - nationalism emerges. It is understood as a principle that requires the coincidence of political and national (cultural) units. Thus, the supporters of the "ethnic" model view the nation as an ethno-social community, which is characterized by the formed consciousness of its identity and the only unified, national culture. At the same time, the nation is relatively independent, stable and at the same time a dynamic ethnic-social organism, capable for self-reproduction, even if it has not created its own state. However, in this case, the nation has an unfinished structure, since it lacks a political superstructure. At the same time, the formation of a nation is inextricably linked with its sovereignty, the transformation of the nation-ethnos into an independent subject of its own political history. The supporters of the "ethnic" model regard all nations as objectively existing ones which created their own states in their continuous existence (so-called historical nations), and those who survived or endure a break in their development. The latter, having lost their national consciousness, are in a state of peculiar sleep.

Substantial (primordialist) approach to the study of ethnic phenomena and their linguocommunicative component seems to be preferable to constructivist (situational, relativistic, instrumental) one because in the case of the absolutism of constructivist approaches, that is, when ethnicity is seen only as an unsubstantiated grouped constructed function, the subject of the study disappears. At the same time, it must be recognized that, despite all the 
apparent opposition, the mentioned approaches need to have common grounds, since they deal with the same social phenomenon, but manifesting in various historical and cultural realities. With the support of the historical approach, let us study the ethnos not as a static state, arbitrarily pulled out of the stream of ethnic history, but as a substantive prerequisite of concrete historical sociality, primary in relation to the social forms embodying it [14].

In the light of the discussing ethnic and national interests, the ambivalent nature of ethnicity and nation should be mentioned. Ethnicity, on the one hand, divides nations and humanity into individuals, but, on the other hand, unites all the people of the same origin (real or imagined) into ethnic communities with common and specific values and interests.

The formation of ethnic interests as a set of specific interests inherent to a particular ethnicity and/or ethnic group is carried out due to its inequality and/or dissimilar place and role in social and political life. Ethnic interests are a real cause of the behaviour and activities of ethnic communities. They are aimed either at preserving and strengthening the existing status or improving it. Ethnic interests in mono-ethnic democratic societies coincide with national interests, whereas in multiethnic and especially multinational states, they may contradict or conflict with.

Nations split the ethnicity and humanity into individuals, and, on the other hand, they unite people, regardless of their ethnic origin, social status and religious beliefs, in ethnosocial political communities at a time. Naturally, there may be certain contradictions and rivalries between the ethnos and the nation, as well as between the ethnicity, the nation, and the state. National interests are not only the sum of interests of different individuals, social or ethnic communities, which constitute the society, rather a generalized reflection of their essential needs and natural set. In democratic mono-ethnic and one-nation states, where political nations have been formed, national interests are considered to be higher than class, ethnic and state interests. They are aimed at achieving the unity and territorial integrity of the state, creating favourable conditions for the development of economic, political and spiritual fields of society's life. In multinational (multiethnic) states, which, moreover, are multiethnic, the intricacies of different interests, and a lot of contradictions and conflicts arise due to the dual position of ethnic groups and nations, which, on the one hand, are subjects of political processes, and on the other hand, are objects of state policy. The method and the ability to regulate ethnocultural contradictions that cause centripetal and centrifugal tendencies in social development, above all, depend on the type of world order.

The well-known statement of S. Huntington declares that the modern world order is based on civilizations: societies that have cultural similarities co-operate with each other; attempts to shift the society from the conditions of one civilization to the context of others are infertile; countries are grouping around the leading or core countries of their civilizations. Consequently, the main thing in intercultural relations, in his opinion, is the awareness of different cultural identities, which coincides with the identity of civilization $[3$, p. 13]. And if earlier civilizations were separated by time and space, nowadays in the conditions of globalization these obstacles are eliminated. In the XX c. the relationships of civilizations changed. The phase of the unidirectional influence of one civilization on the others was changed with the stage characterized by intense, continuous and diverse relationships among all the civilizations [3, p. 67]. In addition, the author highlights another tendency in the communication of various cultures, which relates to the presence of representatives of non-Western cultures in the West. In this case, the challenge to Western culture comes from emigrants of other civilizations who refuse to assimilate and continue to remain faithful to the spiritual values, customs and culture of their native countries and pass them from generation to generation [3, p. 497]. Such type of a conflict is observed now in the USA, EU countries, as well as in the territories of the former Soviet republics.

Analysing this tendency, J. Habermas distinguishes between "national identity" and "nationalism". He writes that the form of national identity makes it necessary for each 
nation to be shaped in the state for the sake of gaining its independence. However, there are few states with a nationally homogeneous population. And conquering of national minorities by a national state is a manifestation of nationalism that gives rise to the struggle of these minorities for their rights to national self-determination [4, p. 120]. In our opinion, the author mistakenly identifies the "nation" and "ethnos", because the nation is a sociopolitical entity irrespective of the ethnic composition of citizens, and the ethnos is the bearer of a particular culture (languages, traditions, customs, etc.). But in another work, Y. Habermas notes that the political mobilization of subjects also requires cultural integration of the population hastily summoned for the first time [4, p. 277]. That is, it is already about the need to create a nation of a common culture, which forms the cultural symbols of the people.

Speaking about the cultural identity of an ethnic group, it is important to understand what is consciously accepted by the ethnic community, and what belongs to the unconscious elements of ethnic culture and is lost in the depths of the ages as archetypes of culture discovered for the scientific community by K. Jung. Cultural identity is based on a certain type of mentality that contains both conscious and unconscious cultural codes, defining the integrity of the life of an individual and the community with which the individual identifies himself.

The concept of mentality was developed and continues to be studied in psychology, anthropology, ethnology, philosophy, structural linguistics, etc. Researchers find different content in it, but for all of them it is indispensable that mentality must be derived from the cultural and historical development of each ethnic group: the natural and geographical conditions of its existence, home life, myths, language, beliefs, etc. In modern philosophical literature, mentality is defined as the deep level of collective and individual consciousness, which contains the unconscious; relatively stable set of attitudes and tendencies of an individual or social group to perceive the world in a certain way. Mentality is formed depending on the traditions of culture, social structures and the entire environment of human life, and in its turn forms them, acting as a generative beginning [7, p. 525]. This kind of understanding points to the dialectic nature of the ethnic culture and mentality, since the cultural forms of life of a certain ethnic group arise as a result of quite certain conscious and unconscious components of the mental activity of people in their interaction, and at the same time, cultural forms transform the mentality of this ethnic community.

As follows from the nature of the mental phenomenon, rapid social changes have to turn into archetypes, into unconscious automatisms, to become the content of ethnic mentality. Hence, there is the difference in the pace and rhythm of changes in ideology and mentality: the ideology quickly responds to the slightest changes in the society, affecting the interests of an ethnic or a social group; ethnic mentality is more stable, inactive and conservative due to its genetic conditionality. Therefore, it should be concluded that there is a certain praxeological limitation of its use in the process of social reformation.

So, the adoption and sustainable entry of foreign influences into the culture of the ethnos, even in a fundamentally revised form, or their rejection and oblivion, are the subject to certain laws. And the criterion used here, first of all, is compliance with the "spirit of the people", its ethno-cultural values. In the body of the culture of an ethnos there is always a certain core of stable, inherently unique phenomena, structures and values that are ethnically specific. It is this core that performs the differentiating function (with the help of the antithesis "we - they", the creation of ethnic stereotypes, in a word, by opposing the native community to all the others). But it also plays an ethno-integrating role, uniting the members of the ethnos, even if due to their historical destiny they are scattered throughout the world. In this regard, the mentality is not a property inherent in the individual initially, but the ways of relationships that are formed are fixed only in the course of social 
interaction both in the environment and the condition of its existence. Here we should especially emphasize the role of historical / mythological knowledge and experience as a system-forming part of social memory (traditions, customs, etc.).

Once crystallized, the mentality is maintained, mutated by social relations. At the same time, the social processes associated with the formation and maintenance of mentality are determined by the social structure. Conversely, the mentality, born due to the interaction of individual consciousness and social structure, reacts to the social system, supporting, optimizing and modifying its main features and characteristics.

Since a language is the most important mode of transmission and way of being mentality, let's find out in which way the mentality of people affects the nature of their communication in multicultural societies.

V. von Humboldt, reflecting the cultural and historical origins of the language of a certain people, showed its place in the culture. In particular, he noted that language is the body of inner being and even this being itself, so step by step it reaches internal clarity and external incarnation. With all the subtleties of its roots, it has grown up with the force of the national spirit, and the stronger the influence of the spirit on the language, the more regular and richer the development of the latter is. In all its interweaving, it is a product of the language consciousness of the nation, and therefore the basic questions of the origin and inner life of the language could be answered by appealing to the spiritual force and national force and national identity [8, p. 47]. And despite the fact that von Humboldt does not use the word "mentality," in fact, he means it when he speaks of "the spirit of the people", "the linguistic consciousness of the people," their "spiritual strength and national identity." It follows from the above passage that the thinker considered the language of the people (and in his writings, the words "people" and "nation" are used synonymously) by the quintessence of its identity, and in our terms, the mentality of the people.

However, ethnic identity, mentality imposes a certain framework on language connected with that aspects of mentality, in particular, with the mental composition, the temperament of the people, the symbols underlying the system of his spiritual values, in particular myths and religious beliefs, traditions, etc., to which the imprint of the naturalgeographical and living conditions of his life is imposed. Mentality forms a specific type of ethnic culture. As Ukrainian philosophers S. Krymskiy and Yu. Pavlenko state, culture is primarily a worldview self-expression of the ethno-historical community of people, which reflects the specific conditions of the existence of this collective in the form of traditions, persistent value orientations and normative patterns of thinking and behaviour of people [9, p. 170]. And all these components of mentality to a certain extent are expressed by the linguistic means of an ethnic group.

Every language community uses certain means of communication: languages, their dialects, jargons, and stylistic varieties of a language. Any such tool can be called a code. In the most general sense, a code is a means of communication: natural languages and artificial languages (Esperanto, machine language, Morse code, marine flag signalling, etc.). Along with the term code the term subcode (territorial dialect, urban koine, pidgin, lingua franca, etc.) is used. The term subcode denotes a variety, a subsystem of some common code, a communication tool of a smaller size, a narrower scope of use, and a smaller set of functions than the code. The totality of codes and subcodes, historically developed and used in this ethno-linguistic community and located with each other in the relationship of functional complementarity, is called the lingo-communicative system of this community. Each of the codes and subcodes that make up a social-communicative system has its functions that do not overlap with the functions of other codes and subcodes, thus they all complement each other in functions. In a multilingual society, a linguistic-communicative system is formed by different languages, and communicative functions are distributed among them. 
The main subsystems of communicative ethnocultural space, understood as a historically formed ethno-socio-linguistic community, characterized by relatively stable and regular internal communication links and territorial localization, are the regulated as well as non-regulated areas of communication.

The first subsystem (language policy) satisfies ideological needs with auto-censorship (control) and serves as the "censored" communicative sphere. To propagate the concept of "a single state - a single nation - the only national language", one of the autochthonous languages is cultivated to suppress the sprouts of ethnonationalism and regionalism, with the help of which cultural and political unity and metaethnopolitical community are created.

The history of Western European culture shows that most countries have chosen the languages of the former metropolises as the language of official communication and as an ideal means of communication both within the country and in communication with the whole world, since they are more universal in comparison with their domestic languages. Therefore, nowadays many scientists pay much attention to the problems of the development of these languages, not only within countries, but also beyond their borders. It is known that functioning and developing in new conditions very different from the original sociocultural ones, they differ a bit from metropolitan standards and develop in the former colonies along a slightly different path than at home.

Sometimes the language of any minority is recognized as the second state language, but more often it is used only at home, in the church and in private schools. The nomination of the autochthonous language for dominant positions is hampered by its "unpreparedness" for the role of the official language, the language of school instruction, science and technology. The linguistic unpreparedness of these language is largely due to their direct suppression or relegation to the role of everyday colloquial languages in the period of colonialism as a result of the wide use of the languages of metropolitan countries, and requires the adoption of linguistic measures for their accelerated development and enrichment.

The second subsystem of everyday communication is marked by the lack of autocensorship, that is, linguistic self-control and it serves the usual "spoken language". It forms a sphere of everyday communication, which includes a personal or personally oriented discourse, which implies that the speaker acts as a personality, with all his/ her personal characteristics and peculiarities.

As it has been already mentioned, the codes (languages) and subcodes (dialects, styles) that make up the social and communicative system are functionally distributed. This means that the same contingent of speakers who make up a given language community, owning a common set of communication tools, uses them depending on the conditions of communication. In other words, according to the sphere of communication, the speaker switches from one language medium to another.

A similar picture is observed in those societies that use two or more languages. The most typical situation is the usage of two or more languages by communicators within the administrative-political region (country), i.e. the situation of bilingualism (polylinguism).

Bilingual people are those who speak two or more languages depending on the conditions of communication. For example, one language is used in an official setting in the presence of the authorities, while another one is used in everyday life contact with family members and neighbours. And in this case, you can talk about switching from one 
language (code) to another (code). Switching codes in the speech of bilinguals is motivated; although there is a mixture of codes that is not motivated. The boundary of codes can be traced within a word combination.

Switching of codes is the transition of a communicant in the process of communication from one language (dialect, style) to another, depending on the communication conditions. The mechanisms of code switching provide mutual understanding between people and the relative comfort of the process of speech communication. On the contrary, the inability of an individual to vary his communication depending on his conditions, adherence to only one code (or subcode) is perceived as an anomaly and can lead to communicative conflicts.

The problem of integration of ethnic cultures is substantially updated in the migration processes of a significant part of ethnic groups in a different cultural environment. On the one hand, in search of a better fate, migrants seek to adapt to the cultural realities of their new social settings, and, on the other hand, almost at a subconscious level, migrants tend to keep the cultural forms of their ethnic group (language, customs, traditions, ceremonies, beliefs, clothing, etc.) to maintain spiritual unity with their community. This dichotomy of adapting migrants to new environments causes many obstacles of both objective and subjective nature, which causes confrontation between migrants and the local population of a given country. The collision of irreconcilable mentalities, whose roots are in the difference in the ways of life of their carriers lies at the heart of almost all types of confrontation - political, religious, linguistic, social and everyday [11, p. 32]. Conflicts on the interethnic, intercultural grounds, in our opinion, lie in the plane of inequality of the value-semantic fields of ethnic cultures, and hence, the inability to perceive the values of another culture on the emotional level of mentality and to accept them at a rational level.

Most often, ethnic stereotypes, produced during a long period of vital activity of a certain people, become ethnically sterile on the way of understanding between representatives of different ethnic groups. They are the standardization of representations of the majority of a certain ethnic group about representatives of another or their own ethnic group, in which generalization and hyperbolization of certain elements of the mentality of the corresponding ethnic groups takes place. As L. Krysin rightly states, in such cases the objects of evaluation may be national customs and traditions, models of everyday behaviour, features of a national character, peculiarities of anatomy, speech, etc. [12, p. 451]. The most vividly ethno-stereotypes are manifested in intercultural communication through everyday speech in which language expressions are deliberately or unconsciously used, in which both a positive or a negative attitude are expressed towards representatives of certain ethnic groups.

As it has been already noted above, globalization intensifies the migration processes in the world, which complicates everyday life in multicultural societies. As a rule, Western countries become polycultural. On the one hand, the inhabitants of the former colonies of these countries migrate here because they can communicate in English, French, Italian and other Indo-European languages learned during the rather long colonization of their countries. On the other hand, representatives of Eastern European countries after the collapse of the Soviet Union and the socialist camp migrate here, often illegally, in search of higher earnings and better living conditions. The migrants carry not only ethnic stereotypes with them, but also the desire to preserve their ethnic identity, often associated with a particular religion. In such multicultural societies, the problem of mutual tolerance is rather acute, because in one place or another, with the slightest misunderstanding, there are interethnic, intercultural encounters with the perspective of the usage of weapons. And since the basis of ethnostereotypes is, as K. Jung notes correctly, "archetypal forms that are based on instincts and express them" [13, p. 83], they are rarely perceived by their carriers, because they have the very "psychic" (K. Jung) representatives of each ethnic group. That 
is why they are least exposed in everyday intercultural communication, and therefore - in preventing social conflicts on an ethnic basis.

However, many researchers of language and intercultural communication point out not only the difference between ethnic languages and cultures, but also the commonality of language and cultural forms of different peoples. The first includes categories declaring the most common, attributive characteristics of objects included in human activity. They act as the basic structures of human consciousness and are universal in nature, since any objects (natural and social), including symbolic objects of thought, can become objects of activity. But apart from them, special types of categories are formed and they function in the historical development of culture, through which the definitions of a person as the subject of an activity, the structure of his/ her communication, his/ her relation to other people and society as a whole, the goals and values of social life are expressed. They form the second block of universals of culture. Between these blocks of universal culture there is a mutual correlation, which expresses the relationship between subject-object and subject-subject relationships of human life activity.

Interethnic communication requires the use of a single language common to communicants. Otherwise, there is a high probability of communicative misunderstanding. The earliest mention of a single language refers to an ancient society. Thus, the Stoic philosophers dreamed of a utopian city-state of Ouranopolis, where all the inhabitants would speak in a special artificial language.

While considering the choice of the principle of linguo-cultural acculturation, attention should be paid to the law of the competition of languages: the development of language depends on the political, demographic, military and economic power of the people who speak it. The current position of languages in the world system is also determined by the relationship of power. Domination of a specific language is never established on its own, because of its special merits, but is the result of political will at different levels: global, regional and national-state.

Today, it is not the territorial position that is important for the interaction of languages, but the access to information technologies, as well as the level of information and technology competence of communicants. There are more and more opportunities to overcome the language barriers. Modern culture is often called "screen culture", which replaced oral and written one. A new stage of development of civilization, becoming "civilization of vision ", "screen civilization", linked with the latest discoveries in the field of communication technologies that most directly affect the nature of the reproduction of culture, methods of its transition. For example, one of the features of electronic communication, which is possible due to the increase in the productivity of communication devices, is "multimodality". Multimodality implies the simultaneous use in communication of means of different semiotic systems. The multimodal communicative process includes two components: verbal (natural language, speech) and non-verbal (other sign systems auditory, visual, etc.) codes.

The combination of the verbal code with codes of other semiotic systems speeds up and increases the effectiveness of communication, since the information and pragmatic capacity of non-verbal means is higher than that of verbal ones. Multimodality is especially important in the context of multilingual communication, allowing it is much easier to overcome the language barriers, because a variety of paralinguistic elements, visual and audio images provide a better understanding of interlocutors from different countries.

The impact of modern Information-Communication Technologies on communicative practice is expressed as the reduction of the lexical fund, the simplification of grammar and 
the increase in the share of emotional content of the statements compared to the proportion of rational content, as well as the vulgarization of speech.

At the same time, in the cultural space of the Network artificial words and expressions are created, which seem to have a basis in natural languages. On the one hand, these artificially created means are used with metaphorical meanings, and on the other, they deliberately transform the form of these words and expressions by breaking the spelling. Sometimes this leads to the emergence of new genre-stylistic hybrids such as "infotehnament", "infomerization", or educatainment. The use of artificial machine language, which requires the unification of linguistic units and the content of the words of the computer language, leads to the transformation of not only speech, but also its functions in the process of using the computer as a means of communication. M. Derry in this context rightly notes that in cyberculture the computer managed to destroy the traditional distance between a word and a deed, because words read on the computer screen not only inform but rather provoke actions [2, p. 93].

In the conditions of globalization of almost all spheres of social life, the common principles of the cultures of the peoples contribute to the mutual understanding of people belonging to different ethnic groups. But at the same time in these processes it is important to understand not only the "constellation of opportunities of ethnic unity, but also the situation of impossibility. After all, if ethnic conflicts affect the archetypal level of mentality of certain peoples, then, in any case, they should not be reduced, but to breed (that is, to seek their autonomy). And, conversely, in political or social conflicts of ethnic groups with solid experience of coexistence, one can hope to overcome any differences on the road to their integration" [1, p. 212].

\section{Discussion}

In the context of mobility increase of the population from economically depressed countries there is growing cultural differentiation of people within most modern urbanized multicultural communities. Both lead to a constant transformation of models and concepts of the policy of managing cultural diversity, as well as taking into account the interests of many of its subjects. These circumstances require an active search by the world scientific community for scientific approaches to conceptualization of new processes of linguistic and cultural diversity. That will allow them to work out the concept of maintaining a balance between the imperatives of openness, development and security, taking into account the specifics of the ethno-mental features of various socio-cultural entities.

\section{Conclusion}

Ethnic mentality as the nucleus of stable, inherently unique phenomena, structures and values consolidate ethnophores into one social integrity at all stages of the development of communities of socio-ethnic series. Since the language is the most important mode of transmission and way of being of mentality, language tools play a significant role in intercultural interaction. It contributes into the processes of ethno-differentiation and ethnointegration.

The realities of the globalized world are encouraging both representatives of the dominant ethnic groups, and immigrants, representatives of other ethnic groups, to produce new forms of intercultural communication in the common space of life. These forms, on the one hand, promote the preservation of ethno-linguistic identity and, on the other, ethnolinguistic unification. $\mathrm{Bi} /$ polylingvism plays a special role in the formation of new forms of interethnic interaction. Although it does not narrow the distance between different ethno- 
cultural fields, but at least it promotes their coexistence on the basis of mutual respect for the cultural features of each ethnic group.

Computerization of all spheres of social life contributes into the dissemination of universal languages, representing universal human cultural values in a multicultural society. Thus, the number of communication participants is increasing, which increasingly use artificial Internet language. In Internet space there are rather well-established groups of communicants that produce a specific language of communication in their narrower virtual environment. The mutual intersection of these spaces eliminates those ethno-cultural obstacles that interfere with normal intercultural communication. The usage of social networks in interethnic communication forms new cultural communicative traditions, common to all members of the multicultural society, which are echoed with existing ethnological realities.

According to the authors' opinion, new forms of communication to a greater extent, are related to the young generation of people belonging to different ethnic groups. The young generation is close to modern forms of mass culture, broadcasting via new electronic means of communication.

\section{References}

1. S. Krymskij, Mudrecy vsegda v men'shinstve (Stat'i raznyh let) (Izdatel'skij dom Dmitriya Byrago, 2012)

2. I. Wallerstein, The End of the Worlds as We Know it: Social Science for the TwentyFirst Century (Logos, 2004)

3. S. Huntington, The Clash of Civilizations and the Remaking of World Order (AST, 2007)

4. Ju. Habermas, Politicheskie raboty (Praksis, 2005)

5. F. Fukuyama, The Great Disruption: Human Nature and the Reconstitution of Social Order (AST, 2003)

6. N. Polyakova, XX vek v sociologicheskih teoriyah obshestva (Logos, 2004)

7. V. Vizgin, Novaja filosofskaja jenciklopedija 4(2), 525-526 (2001)

8. V. fon Gymboldt, Izbrannye trudy po jazykoznaniju (Progress, 2000)

9. S. Krymskij, Ju. Pavlenko, Tsyvilizatsiinyi rozvytok liudstva (Feniks, 2007)

10. A. Vezhbickaja, Jazyk. Kul'tura. Poznanie (Russkie slovari, 1997)

11. A. Percev, Filosofskie i lingvokul'turologicheskie problemy tolerantnosti (OLMAPRESS, 2005)

12. L. Krysin, Filosofskie i lingvokul'turologicheskie problemy tolerantnosti (OLMAPRESS, 2005)

13. K. Jung, Synchronicity an Acausal Connecting Principle (AST, AST MOSKVA, 2010)

14. S. Rybakov, Jetnograficheskoe obozrenie 1, 3-22 (2001)

15. T. Kalniuk, Visnyk NAU 2(22), 14-16 (2015) 